\title{
INFORMAÇÃO, EDUCAÇÃO E TECNOLOGIA: UM BLOG PARA O PROFESSOR DE PRESIDENTE PRUDENTE E REGIÃO
}

\author{
Bruno Góes Saia, Fernanda Sutkus de Oliveira Mello \\ Universidade do Oeste Paulista - Unoeste, curso de especialização em Mídias Digitais Interativas, Presidente Prudente, \\ SP. E-mail: brunosaia@gmail.com
}

\section{RESUMO}

Neste trabalho será desenvolvida uma mídia digital interativa do tipo blog, que terá como principal função informar aos professores de ensino médio e superior, das redes pública e particular, sobre novidades na área da educação a nível nacional, estadual e também internacional, além de divulgar e apoiar o desenvolvimento de iniciativas inovadoras nas escolas de Presidente Prudente e região, especialmente no que se refere ao uso da tecnologia dentro e fora da sala de aula. As características do blog como ferramenta educacional e os seus diversos usos por educadores também serão abordados no trabalho. $O$ artigo pretende analisar como as mídias digitais interativas, em especial o blog, são utilizadas pelos professores, principalmente na região de Presidente Prudente e de que maneira, a produção de uma peça prática que oriente a respeito do uso dessa ferramenta pelos educadores, pode contribuir com o desenvolvimento do trabalho destes profissionais.

Palavras - chave: Informação; educação; tecnologia; blog; Presidente Prudente.

\section{INFORMATION, EDUCATION AND TECHNOLOGY: A BLOG FOR TEACHERS IN PRESIDENTE PRUDENTE, AND SURROUNDINGS.}

\begin{abstract}
This paper will be developed as a practical piece (blog), which primary function is to inform high school teachers and university professors, from public and private schools about news in the field of education at national, state and also international levels. It will also publicize and support the development of innovative initiatives in Presidente Prudente schools and also in the region, especially in regards to the use of technology in the classroom. Especifying the blog features as an educational tool and its uses by educators will also be a subject of this work. In addition, the article also intends to analyze how the interactive digital media, especially blogs, are used by teachers, especially in the area of Presidente Prudente and how, the production of a practical piece to guide on the use of this tool by educators can contribute to the development of the work of these professionals.
\end{abstract}

Keywords: Information; education; technology; blog; Presidente Prudente. 


\section{INTRODUÇÃO}

A crise constante pela qual passa a educação, tanto no Brasil, quanto em outros países do mundo, fez com que este se tornasse um dos setores que mais receberam reformas recorrentes, sem que essas trouxessem resultados positivos e apresentassem avanços de fato. Este conceito, destacado por Tedesco (1998), foi a pedra fundamental deste trabalho, que pretende, desde o início, apresentar ferramentas práticas para que o professor possa utilizar a tecnologia dentro da sala de aula.

Neste sentido, entre as mídias digitais interativas que podem ser utilizadas com o intuito de trabalhar e desenvolver o uso da tecnologia na educação, o blog se apresenta como uma das ferramentas de maior abrangência e que permite o seu uso de maneira bastante aprofundada, sem que seja necessário o conhecimento de linguagem de programação ou outros conhecimentos técnicos da área de informática.

Implementar um blog informativo cujo conteúdo irá tratar de educação nos ensinos médios e fundamental, em Presidente Prudente e região, destacando pontos de interesse deste público, especialmente na área relativa à tecnologia de educação é o principal objetivo do trabalho.

\section{METODOLOGIA}

A pesquisa bibliográfica foi o caminho para o desenvolvimento deste trabalho, utilizada de maneira que trouxesse embasamento teórico necessário para corroborar a teoria de que o blog, entre as mídias digitais interativas, pode ser uma ferramenta importante na divulgação de informações sobre o uso de tecnologia em sala de aula, que sirvam também para estimular a sua prática pelos docentes. A pesquisa bibliográfica foi usada, além disso, para o levantamento de bibliografia a respeito da história do blog, com a intenção de contextualizar a ferramenta a ser apresentada como conclusão do trabalho e também para a definição dos aspectos técnicos referentes ao blog.

Uma pesquisa empírica foi feita, pela internet, para levantar como os professores utilizam o blog e de que maneira o uso da ferramenta está relacionado ao trabalho desenvolvido por eles dentro e fora de sala de aula.

\section{RESULTADOS}

Definir o estilo do blog é um dos pontos primordiais antes de dar continuidade ao seu desenvolvimento. Levando em conta que a intenção deste trabalho é atingir um público de 
professores, um estilo formal deve ser adotado, mas sem deixar de manter alguns aspectos mais 'leves', que facilitem a aceitação destes leitores e estimulem o prazer em lê-lo (EVANGELISTA, 2013).

O administrador e autor será o próprio pesquisador, aproveitando a formação como jornalista, que oferece os recursos e as fontes necessários para garantir a periodicidade e a atualidade das postagens, dentro do cronograma proposto neste projeto. O público alvo do blog serão os professores, estudantes universitários, especialmente os que se preparam para iniciar a carreira na área de docência e também gestores de educação, pedagogos e outros curiosos.

O tema principal a ser abordado pelo blog será o uso da tecnologia, em seus diversos aspectos, dentro e fora da sala de aula. Tutoriais apresentando determinadas ferramentas, discussões sobre suas aplicações e relatos de experiências realizadas na região de Presidente Prudente e em outros locais do país e do mundo serão alguns dos temas abordados.

As postagens serão sempre assinadas pelo autor e terão especificadas as possíveis referências quando utilizados textos ou outros materiais produzidos por terceiros. A periodicidade das postagens será semanal, para permitir que cada material seja desenvolvido de maneira detalhada e cuidadosa e elas serão publicadas sempre aos domingos, um dia no qual os professores costumam estar fora das salas de aula e podem aproveitar o tempo disponível.

"Segundo a regra clássica, o nome deve ser curto, marcante, simples" (EVANGELISTA, 2013). Levando essa premissa em consideração e também a ideia da personificação relacionada aos blogs, apontada anteriormente, surgiu o nome: 'SAIA Educando', que faz referência ao sobrenome do autor, além de transmitir uma noção de movimento, com o verbo utilizado no gerúndio e ainda ressalta o tema da educação, que é o cerne do trabalho desenvolvido.

"Uma frase que unifique o significado do objeto!" (EVANGELISTA, 2013), é a definição de slogan apresentada pelo autor e, também levando em conta essa definição, o slogan: 'Um blog sobre educação e tecnologia de Presidente Prudente e região' foi vislumbrada como uma alternativa interessante a ser utilizada neste contexto, resumindo o conceito a ser trabalho pelo blog, de forma simples e direta, além de especificar o seu público alvo e a região onde estará inserido.

A cor azul "possui grande poder de atração e é utilizada para acalmar o ser humano" (SUTKUS, 2013, p. 22). Essa característica foi levada em conta na escolha desta cor para compor o plano de fundo do blog, além do fato de ela ser uma cor primária. O alaranjado será utilizado em alguns detalhes do blog, por se tratar da cor complementar ao azul, e será utilizado com a intenção de trazer harmonia e garantir os contrastes na identidade visual do blog. 
A fonte a ser utilizada no título do blog será a Syncopate que, segundo descrição do Google Fonts, suas formas apresentam características modernas e não possuem serifas, o que também a inclui entre as variações de fontes mais utilizadas atualmente. Para os títulos e conteúdos das postagens será utilizada a fonte Arial, também por suas características modernas e pela familiaridade que ela já carrega junto aos leitores.

A definição do endereço do blog foi de acordo com a disponibilidade do endereço no domínio Blogger, com a exata reprodução do título do blog, ele será disponibilizado no endereço eletrônico: http://saiaeducando.blogspot.com.br

Definidas a identidade visual, as cores e as fontes a serem utilizados no blog, foi desenvolvida a estrutura inicial a partir do modelo mais simples apresentado aos usuários do Blogger. Uma imagem de fundo foi então selecionada, dentro das opções apresentas entre os modelos, a qual predomina a cor azul e utiliza de recursos gráficos que fazem referência ao tema da tecnologia.

Foi então modificada a fonte do título e, para facilitar a visualização e criar maior equilíbrio na página, foram aumentados os tamanhos das fontes, tanto do título, como também do restante do corpo do corpo do blog.

Algumas ferramentas (gadgets) foram adicionadas, para auxiliar a navegabilidade da página pelos leitores. Todas estão posicionadas à direita da área onde são publicadas as postagens e, em primeiro lugar está a ferramenta para pesquisa no blog, em seguida, o perfil do autor, seguido pelo arquivo do blog, disponibilizado em ordem cronológica. Logo depois foi inserida uma ferramenta que apresenta os marcadores mais utilizados nas postagens, seguido pela opção 'siga pelo e-mail' e, por fim o total de visualizações da página.

Na sequência, uma primeira postagem foi publicada no blog, com um texto curto, de apresentação e explicação a respeito de sua usabilidade e periodicidade e o resultado é apresentado abaixo: 


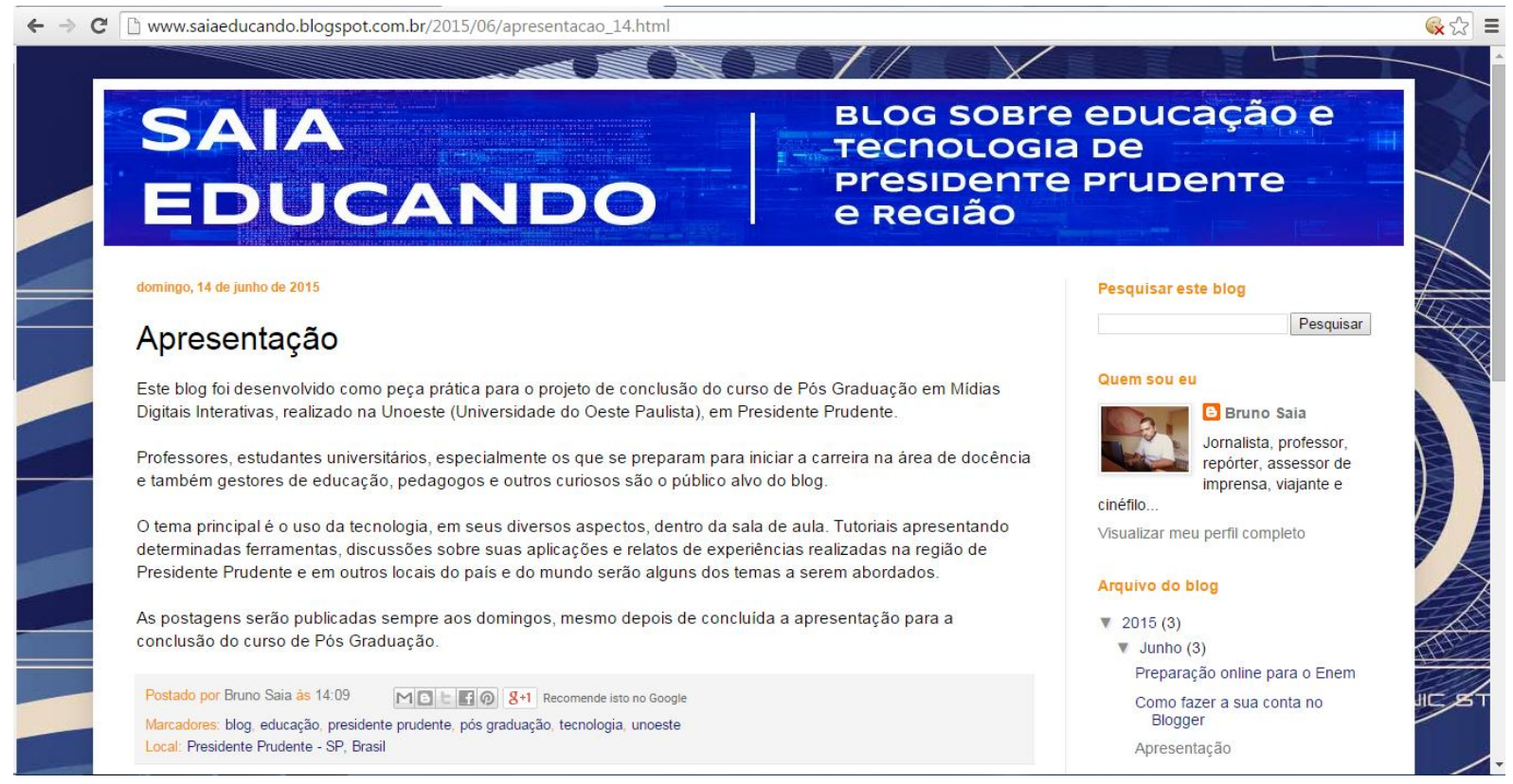

Fonte: Em: <http://saiaeducando.blogspot.com.br/>, Acesso em 02 julho 2015

\section{DISCUSSÃO}

Uma reflexão a respeito da relação entre educação, competitividade e cidadania na sociedade moderna, destacando a atenção para a crise no sistema tradicional de educação e para a necessidade do desenvolvimento de uma nova escola, que tem o professor como produtor/desenvolvedor de conteúdo tecnológico, cujo objetivo final é a transmissão de conhecimento levando em consideração a formação de indivíduos completos é um ponto fundamental para o desenvolvimento da educação (TEDESCO, 1998).

Aliado a isso, à necessidade de se preparar indivíduos que se tornem seres humanos completos e não apenas instrumentos para uma economia de mercado é um dos principais pontos levantados por (TEDESCO, 1998) como uma possível perspectiva de solução futura para a crise vivida pela educação e por outros segmentos da sociedade.

"Indivíduos com conhecimentos e habilidades mais amplas e profundas, que saibam aprender a aprender, com capacidade de julgamento crítico e domínio básico dos três pilares do saber: matemática, ciência e tecnologia" (TEDESCO; 1998, p. 50), é algo necessário para que o aluno esteja preparado para ser inserido de maneira satisfatória na dinâmica da sociedade moderna, além de conhecimentos de cultura humanística e de disciplinas socioeconômicas.

"Além de resolver problemas, os alunos deveriam ser treinados a analisar por que ele surgiu e como ele se relaciona com outros problemas existentes ou potenciais" (TEDESCO; 1998, p. 51). Neste sentido, o autor destaca também que este desenvolvimento pode ser atingido a partir 
da experimentação, processo no qual os estudantes aprendem a aceitar a responsabilidade de sua própria aprendizagem e também por meio do trabalho em equipe, que estimula a aquisição e o desenvolvimento de conhecimento em grupo e não por meio da competição individual.

Solidariedade, participação, criatividade, pensamento crítico são alguns dos pontos específicos levantados na referida obra como fundamentais no desenvolvimento do estudante (TEDESCO, 1998). Levando em conta a importância da multidisciplinaridade e também do trabalho de maneira interativa, as ferramentas tecnológicas na educação, com enfoque para o uso do blog por educadores, se apresentam como a melhor alternativa para este desenvolvimento.

Neste sentido, a produção e desenvolvimento de um blog, cujo objetivo seja informar, ensinar e apresentar sugestões de maneiras com as quais o professor pode trabalhar com esta ferramenta na prática, tanto dentro da sala de aula, em parceria com os alunos, como também a nível escolar, interligando diferentes classes e apresentando o trabalho desenvolvido por determinada escola se torna uma ferramenta que pode contribuir para desenvolvimento dessa ferramenta, ao menos a nível regional.

A possibilidade de se criar e desenvolver um blog sem custo e sem a necessidade de conhecimento técnico de programação o coloca como a alternativa ideal para que o professor, individualmente ou em conjunto com os alunos, se coloque como produtor/desenvolvedor de conteúdo tecnológico, estimulando a inserção dos docentes neste universo.

\section{CONCLUSÃO}

Ao fim do presente trabalho, com a peça prática concluída e levando em conta que um blog é uma ferramenta mutável e que necessita ser constantemente atualizada, reformulada e também divulgada, para que cumpra a função para a qual foi designado inicialmente, o questionamento feito por mim, é sobre a viabilidade desta continuação, mesmo depois de o Trabalho de Conclusão de Curso de Pós-Graduação em Mídias Digitais Interativas, para o qual ele foi destinado, ter sido finalizado.

A resposta definitiva para esta pergunta apenas o tempo poderá trazer, porém, a intenção é de que esta ferramenta, de fato, mantenha a sua periodicidade nas publicações e que se desenvolva a medida que surjam novos leitores e que ela possa cumprir o seu objetivo de contribuir com a educação na região de Presidente Prudente, especialmente no que diz respeito ao uso da tecnologia.

Garantir a manutenção deste blog destinado aos professores, que será feita pelo pesquisador é também a maneira encontrada para continuar desenvolvendo seus conhecimentos 
a respeito das mídias digitais interativas, às quais se insere a ferramenta blog e para contribuir de alguma maneira utilizando as informações adquiridas no curso de pós-graduação em Mídias Digitais Interativas.

Breves encontros com os professores que lecionam em escolas de região me permitiram ter contato direto com a dificuldade enfrentada por estes profissionais no uso de determinadas ferramentas e também mostrou que existe grande interesse deles na utilização das tecnologias em sala de aula e que isso só não é mais difundido, pois estes professores carecem do conhecimento técnico necessário para realizar este trabalho e, por conta disso, não acreditam em sua viabilidade prática.

Portanto, a presença de um canal de comunicação que promova essa inserção dos professores no universo das ferramentas tecnológicas irá, sem sombra de dúvida, contribuir para o desenvolvimento da educação na região de Presidente Prudente, o que justifica a realização do presente trabalho e, mais ainda, a sua continuidade.

\section{REFERÊNCIAS}

COMSCORE; 2014; Brasil Digital Future in Focus. Disponível em: <http://www.comscore.com/por/Imprensa-e-eventos/Apresentacoes-e-documentos/2014/2014Brazil-Digital-Future-in-Focus-Webinar $>$, Acesso em 02 jul. 2015.

Diretoria de Ensino Região de Presidente Prudente;

Disponível em: <http://depresidenteprudente.educacao.sp.gov.br/> Acesso e 02 Julho 2015.

EvangeBlog. Disponível em: <www.evangeblog.com>, Acesso em 02 jul. 2015.

GOMES, Maria João. Artigo: 2005; Blogs: um recurso e uma estratégia pedagógica; Universidade do Minho; VII Simpósio Internacional de Informática.

Google Fonts (Disponível em: <www.google.com/fonts/specimen/Syncopate>, Acesso e 02 Julho 2015).

Google+, Blogger (Disponível em: <https://plus.google.com/+Blogger/about $>$ 2 Acesso e 02 Julho 2015).

MARCO, Evangelista; 2013; Manual do Blogueiro; Amazon Digital Services.

NOGUEIRA, Luciane Chiodi. 2009; A web 2.0 e a cultura dos blogs; Dissertação (Mestrado em Design) - Universidade Anhembi Morumbi; São Paulo.

TEDESCO, Juan Carlos. Editora Ática; 1998; O novo pacto educativo. 